\title{
A TRAJETÓRIA DE UM SUJEITO TRANSGÊNERO NO CONTEXTO UNIVERSITÁRIO
}

Felipe Santos da Silva ${ }^{1}$

Alexandre Marcelo Bueno ${ }^{2}$

\begin{abstract}
RESUMO: O discurso sobre identidade de gênero revela, em suas nuances, uma trajetória transformadora quando bem-sucedida. Contudo, tal empreitada não é feita por um percurso linear, sem obstáculos e dramas a serem superados. O objetivo deste estudo é analisar os efeitos de sentido presentes no discurso de um sujeito transgênero e as repercussões sociais, positivas e negativas, que o ser trans vivencia no contexto universitário. A análise incide sobre o recorte de uma pesquisa com um número maior de participantes LGBTTQIA+, acadêmicos de uma universidade local, que foram entrevistados ao longo de 2018. O método consistiu em uma análise semiótica dos relatos apresentados nessa investigação, inter-relacionando o campo de estudos de gênero e a transexualidade. Os resultados apontaram um cruzamento temático com o predomínio do preconceito, da intolerância e da estigmatização da comunidade trans, dentro e fora do contexto universitário. Ao mesmo tempo, observamos temas relacionados à descoberta identitária, sua busca por reconhecimento e respeito. A possibilidade de examinar os discursos de vivências desses sujeitos propicia a visibilidade de uma classe identitária que permanece segregada e excluída.
\end{abstract}

PALAVRAS-CHAVE: Semiótica francesa. Transexualidade. Transgeneridade. Preconceito.

ABSTRACT: Gender identity speech may present a revolutionary path when well discussed. However, such a path may not have a linear development, likely to present barriers and issues to be surpassed. The objective of this paper is to analyze the projected meanings on the narrative of a transgender person, as wells as to discuss the social repercussion that such a person faces in the academic context. The analysis will be performed in the selected portion of this speech, which composes the corpus of a greater 2018's study involving the LGBTTQIA+ scholar community. Methodologically, the Semiotics analysis guided the development of this study. Gender and transgender bibliography also added base to this paper, aiding in the analysis of the testimony. The results presented the presence of prejudice, intolerance, and stigmatization in and out of the academic context. At the same time, identity discovery, self-recognition, and respect aspects were unveiled by the analysis. Concluding, the analysis of the narrative also gives attention to matters such as segregation and exclusion of this social group.

KEYWORDS: French Semiotics. Transsexuality. Transgeneration. Preconception;

\section{Introdução}

\footnotetext{
${ }^{1}$ Psicólogo graduado pela Universidade de Franca. Graduando em Pedagogia pela Universidade Metodista de São Paulo. E-mail: felipe.stos.sva@gmail.com.

2 Professor Doutor do Programa de Pós-Graduação em Letras na Universidade de Mackenzie .E-mail: alexandrembueno@gmail.com.
} 
PERcursos Linguísticos • Vitória (ES) •v. 10 •n. 25 • 2020 • ISSN: 2236-2592 • Dossiê:

Discursos de resistência e corpos (re)existentes •

Os discursos identitários constituem, na atualidade, um campo fértil para discussões sobre as configurações dos sentidos na contemporaneidade. Em parte, essas discussões se aprofundam pela entrada da diversidade figurativizada em sujeitos, sobretudo os pertencentes à comunidade LGBTTQIA+, em certos espaços institucionais, como o universitário. Ao mesmo tempo em que se ganha visibilidade, a emergência de problemas, que outrora eram ignorados pela heteronormatividade hegemônica, ganha força por meio das discussões e pesquisas que passaram a ser realizadas nos próprios espaços institucionalizados das universidades.

Dentre os problemas ligados à questão identitária, podemos pensar no acesso à educação ao qual a população LGBTTQIA+ tem ou não direito. No Brasil, somente em 1999 houve o ingresso da primeira mulher transexual em uma universidade pública ${ }^{3}$. Essa situação de restrição ocorre, em grande parte, à existência da discriminação na esfera escolar e universitária, que privilegia o sujeito branco, heterossexual e de classe média, e exclui todos os que não se encaixam nesse padrão estabelecido e construído socialmente como ideal.

Em particular, a estigmatização que acompanha o sujeito trans mostra que, além dos diversos dramas e conflitos internos que ele experiencia no decorrer de um longo e árduo processo de descoberta e (re)descoberta identitária, existem ainda inúmeras barreiras institucionais que se colocam como desafios contra os quais ele deve lutar, como o reconhecimento do direito do uso do nome social; ambiguidades e falta de orientações claras sobre o uso de determinados espaços nas dependências da universidade; estranhamentos e preconceitos de colegas de turmas e professores; falta de compreensão sobre o assunto e incertezas em relação ao modo como se comportar e o que esperar das interações, entre outras questões que atravessam a questão identitária nos espaços institucionais e as relações que eles comportam.

Em contrapartida, temos visto emergir um conjunto que se fundamenta na liberdade de um poder-ser e poder-fazer, que privilegia a ideia de respeito e aceitação do outro em sua diversidade. Se antes havia uma quantidade quase inexistente de pessoas LGBTTQIA+ inseridas em ambientes universitários (pois não assumiam sua condição perante os demais), atualmente esse quadro tem se modificado com o aumento da possibilidade de acesso desses sujeitos à esfera acadêmica ${ }^{4}$. A mudança nesse quadro se deve tanto à luta pelo respeito e pelo

\footnotetext{
3 Notícia disponível em: <http://especiais.correiobraziliense.com.br/violencia-e-discriminacao-roubam-detransexuais-o-direito-ao-estudo $>$.

${ }^{4}$ Segundo informações divulgadas pela instituição de ensino UFABC, 40 vagas são destinadas para pessoas trans, para ingresso nos cursos de graduação da Universidade Federal do ABC, por meio do Sisu. Notícia disponível em: <https://www.redebrasilatual.com.br/cidadania/2020/01/ufabc-vagas-exclusivas-transgeneros/>.
} 
PERcursos Linguísticos • Vitória (ES) •v. 10 •n. 25 • 2020 • ISSN: 2236-2592 • Dossiê:

Discursos de resistência e corpos (re)existentes •

reconhecimento dos direitos à educação, saúde e trabalho (tal como ocorre com os demais cidadãos brasileiros), quanto pelas políticas públicas existentes até poucos anos atrás.

Nesse sentido, o presente trabalho apresenta sua discussão sobre o discurso identitário a partir de subsídios derivados de uma investigação que coletou depoimentos de acadêmicos de uma universidade local do interior paulista. O objetivo foi analisar discursos que aportam as experiências concernentes ao universo acadêmico, ligadas às orientações sexuais e às identidades de gêneros com as quais eles (as) se identificam.

Como recorte teórico, foi utilizada a semiótica discursiva de linha francesa, que nos permite identificar os efeitos de sentido presentes no texto que se constitui nos depoimentos dos acadêmicos. Além disso, a fundamentação teórica desse trabalho dialoga com os estudos sobre gênero, transexualidade, preconceito propostos por Modesto (2013), Butler (2017) e Jorge; Travassos (2018), e os estudos sobre estigma apresentados por Goffman (2004) sob o prisma da antropologia social, uma vez que, dos seis depoimentos coletados durante a pesquisa, recorremos a alguns fragmentos de apenas um dos participantes entrevistados, que elabora considerações sobre a transexualidade e suas interfaces no contexto universitário.

A existência de universitários que vivenciam conflitos relacionados a si mesmos e aos outros aponta para a necessidade do desenvolvimento da pesquisa científica, com o intuito para entender quais são as influências que concebem tais conflitos e lutas identitárias. Além disso, se busca entender quais os mecanismos psíquicos implicados no sujeito que experiencia a autodescoberta, assim como as relações polêmicas/adversas que surgem nas relações entre identidades e alteridades.

Antes da realização da coleta de dados e gravações dos depoimentos, foram lidos o Termo de Consentimento Livre e Esclarecido (TCLE) para os participantes da pesquisa. Assim, todos foram orientados sobre o funcionamento e as diretrizes centrais da pesquisa em relação ao sigilo, à confidencialidade e à liberdade de não continuar no estudo, caso não se sentissem confortáveis no momento das gravações. Por se tratar de uma pesquisa que envolveu seres humanos, foi necessária a aprovação do Comitê de Ética e Pesquisa com Seres Humanos. O número de aprovação CAEE é 88935518.2.0000.5495.

\section{Percursos e percalços identitários}

É importante salientar alguns pontos fundamentais que ancoram a semiótica como prática e como se dá a sua aplicabilidade no corpus que pretendemos analisar. Nesse sentido, orientamo-nos a partir das considerações de Landowski (2012): 
PERcursos Linguísticos • Vitória (ES) •v. 10 •n. 25 • 2020 • ISSN: 2236-2592 • Dossiê:

\section{Discursos de resistência e corpos (re)existentes •}

De fato, a semiótica não sendo para nós uma doutrina, mas uma prática, tentamos praticá-la: falá-la (a palavra de ordem está no aprendizado de segundas línguas) mais que falar dela. Pois bem, como todas as outras linguagens, não só ela está por natureza em devir, mas, sobretudo, deve permitir falar de outra coisa que não dela mesma: de textos-objetos, é claro, e de seus contextos, evidentemente, mas também das práticas reais nas quais estamos diariamente envolvidos. Por exemplo, dessa prática semiótica em situação, que é precisamente a produção da presença do Outro, como tendo sentido (LANDOWSKI, 2012, p. 08-09).

Nesse sentido, praticar a semiótica é compreender o que o texto diz, como diz, o contexto no qual ele se ocorre e implica também a observância das relações e presenças da identidade e alteridade que se que nele se revelam, e como elas se relacionam e interagem entre si.

Com a finalidade de preservar a identidade do depoente, utilizaremos o nome fictício de Gabriel, de maneira que quaisquer informações aqui apresentadas não tragam traços da identidade do participante da pesquisa. No primeiro momento do depoimento de Gabriel, ele se apresentou e contou como ele lida com o seu corpo desde a sua infância, e como foi para ele lidar com as mudanças que ocorreram da infância para a adolescência.

\footnotetext{
Meu nome é Gabriel, eu tenho 22 anos, curso Psicologia, tô no segundo ano de Psicologia, nasci em $* * * * *$ e moro em $* * * * *$.

Da infância, acho que as coisas são sempre iguais assim, a gente não diferencia muito, que corpo é de quem. É, mas aí com o final assim da infância, com uns nove, dez anos, a gente começa a perceber que algumas coisas começam a ficar diferentes assim, porque antes a gente vê corpos e as pessoas que denominam coisas do que a gente é ou não, de acordo com a genital que você nasceu, de acordo com o seu sexo biológico, mas aquilo não tem tanto significado, porque nada muda, as coisas são corpos iguais. Eu me lembro na infância, de achar que eu era como o meu irmão e que nada mudaria, mas aí com a transição para adolescência, as coisas começaram a mudar no corpo, assim fisicamente, porque na minha cabeça as coisas não tinham mudado. Mas aí eu comecei a ter que tentar adequar as coisas, mas na infância era tudo igual, ou eu me percebia como eu sou hoje. Aí depois, eu tive que ter outra percepção (GABRIEL, 2018, trecho 01).
}

Gabriel apresenta os elementos primários que constituem a sua identidade, segundo a perspectiva dele mesmo: seu nome, sua idade, o que estuda. Em seguida, ele relata que não identificava diferenças em relação ao seu corpo com os demais durante a sua infância e imaginava-se como igual ao seu irmão. Pierre Bourdieu (2002) destaca que existem elementos da ordem da percepção e da apreciação em que estão imbricados a constituição do masculino. Após ter a consciência perceptível dessa existência e da demarcação que diferencia, categoriza e hierarquiza os sujeitos homem e mulher:

Estamos incluídos como homem ou mulher, no próprio objeto que nos esforçamos por apreender, incorporamos, sob a forma de esquemas inconscientes de percepção e de apreciação, as estruturas históricas da ordem masculina; arriscamo-nos, pois, a 
PERcursos Linguísticos • Vitória (ES) •v. 10 •n. 25 • 2020 • ISSN: 2236-2592 • Dossiê:

Discursos de resistência e corpos (re)existentes •

recorrer, para pensar a dominação masculina, a modos de pensamento que são eles próprios produto da dominação (BOURDIEU, 2002, p. 13).

Esses elementos que caracterizam a dominação masculina, ou a construção da ideia de uma categoria que se apresenta como superior às demais, constitui modos de existência e de presença que se diferenciam. A partir do depoimento de Gabriel, identificamos a diferença fundamental entre identidade e alteridade (Landowski, 2002). A identidade relaciona-se com o masculino que ocupa o status de dominador, que recebe privilégios e constitui regras e modelos que devem ser seguidos pelos demais. É o que Landowski (idem) chama de Sr. Todo Mundo, ou seja, uma referência identitária padrão, que comporta o que uma sociedade ou cultura identifica como a norma a ser seguida. A alteridade, no caso do discurso de Gabriel, relacionase com todas as demais identidades que não são consideradas masculinas, ou seja, não se trata aqui apenas ou estritamente do feminino, mas de todas as outras identidades de gênero que existem, incluindo o transgênero, transsexual ${ }^{5}$, não-binário entre tantos outros.

O discurso de Gabriel elabora, desde seu início, uma série de temas que podem ser organizados da seguinte maneira: o tema do autodescobrimento identitário, quando a ele ocorre não ser igual à irmã. O tema da sexualidade, quando são apresentadas as figuras "do genital", "sexo biológico" e dos "corpos" que Gabriel começa a se dar conta que são distintos, entre ele e o seu irmão por exemplo. Além disso, observamos o tema de conflito identitário, quando Gabriel se dá conta das mudanças e diferenças em relação ao seu corpo e de sua necessidade em se adequar a elas e ao movimento que lhe causa desconforto, uma vez que ele não esperava ter que lidar com todas essas questões. Por fim, há também o tema de transição da infância para a adolescência, em que Gabriel adquire um novo modo de pensar si mesmo e o Outro, a partir da identificação de diferenças, de necessidades de mudanças e de ajustamento em relação ao seu corpo.

Ainda em relação ao ajustamento, no final da fala de Gabriel ("ter que tentar adequar as coisas", devido às mudanças que começaram a surgir em seu corpo), há um dever-fazer (uma necessidade) que ele não estava pronto para articular naquele momento de sua vida. Somente quando as mudanças começam a surgir, ele se viu obrigado a ter que lidar com elas.

\footnotetext{
${ }^{5}$ Denominamos as pessoas não-cisgênero, as que não são identificam com o gênero que lhes foi determinado, como transgênero, ou trans.

No Brasil, ainda não há consenso sobre o termo, vale ressaltar. Há quem se considere transgênero, como uma categoria à parte das pessoas travestis e transexuais. Existem ainda as pessoas que não se identificam com qualquer gênero, não há consenso quanto a como denominá-las. Alguns utilizam o termo queer, outros, a antiga denominação “andrógino", ou reutilizam a palavra transgênero (JESUS, 2012, p. 10).
} 
PERcursos Linguísticos • Vitória (ES) •v. 10 •n. 25 • 2020 • ISSN: 2236-2592 • Dossiê:

Discursos de resistência e corpos (re)existentes •

Nos momentos finais da fala de Gabriel, ele diz: "mas na infância era tudo igual ou eu me percebia como eu sou hoje". Essa afirmação é muito importante para compreendermos um fato que se apresenta no discurso de Gabriel. Ele nasceu com o sexo biológico feminino e teve que se adequar a isso, ele viu a necessidade de agir de acordo com o que um sujeito do sexo feminino é e experiencia em sua adolescência (puberdade), diferente do sujeito do sexo biológico masculino.

Gabriel afirma que desde pequeno se sentia como homem. Somente em sua adolescência, devido aos fatores físicos e biológicos implicados no sexo feminino e suas mutações físicas e genéticas (desenvolvimento do corpo feminino, crescimento dos seios, primeira menstruação, entre outros fatores fisiológicos), ele teve que lidar com tudo isso (a sua desorientação e o conflito interno = conflito modal entre o saber-ser e o não-poder-ser), em que a modalização do não-poder-ser, está imbricada com as construções e representações sociais previamente construídas, que fazem saber/crer, o não poder ser um sujeito que se identifique em desacordo com a sua constituição biológica, identificando uma incoerência com o autoconceito que ele tinha.

\begin{abstract}
Os momentos de desorientação são vitais. Existem experiências corporais que perturbam o mundo ou arrancam o corpo de suas raízes. A desorientação como uma sensação corporal pode ser desestabilizante, pode destruir a confiança que a pessoa tem em suas fundações ou a crença de que as fundações que temos podem sustentar as ações que tornam nossa vida mais habitável. Esses sentimentos de destruição, ou de serem destruídos, podem persistir e se tornar uma crise. Ou o próprio sentimento pode ser passado, quando os fundamentos retornam ou quando voltamos a esses fundamentos. O corpo pode ser redirecionado se a mão alcançar ou fortalecer uma ação. Ou a mão pode estender-se e não encontrar nada, e pode agarrar a indeterminação. O corpo, quando perde o apoio, pode se perder, se livrar, ser jogado ${ }^{6}$ (AHMED, 2006, p. 217, tradução nossa).
\end{abstract}

Esse conflito interno se refere a um conflito modal interno em torno da categoria do /ser/. Assim, Gabriel sabe-ser homem, mas não-pode-ser homem pelas questões já mencionadas. A falta de uma resolução inicial desse arranjo modal é que leva à percepção de "momentos de desorientação", como menciona Ahmed (2006). De qualquer maneira, o conflito modal leva o sujeito adiante em seu percurso, justamente em busca de uma resolução do

\footnotetext{
${ }^{6}$ Texto original: Los momentos de desorientación son vitales. ay esperiencias corporales que trastocan el mundo, o que arrancan al cuerpo de sus raíces. L desorientación como sensación corporal puede ser desestabilizadora, puede destruir la confianza que la persona tiene en sus fundamentos, o la creencia en que los fundamentos que tenemso pueden sostener las acciones que hacen nuestra vida más vivible. Estos sentimientos de destrucción, o de estar destrozada, pueden persistir y convertirse en una crisis.

$\mathrm{O}$ el sentimiento mismo puede pasarse, cuando los fundamentos vuelven o cuando volvemos a esos fundamentos. El cuerpo puede ser reorientado si la mano que se tiene alcanza ao para afianzar una acción. O la mano puede tenderse y no encontrar nada, y puede en cambio agarrar la indeterminación del aire. El cuerpo, cuando pierde su apoyo, puede perderse, deshacerse, verse arrojado. AHMED, S. Queer phenomenology, London: Duke University Press, 2006.
} 
PERcursos Linguísticos • Vitória (ES) •v. 10 •n. 25 • 2020 • ISSN: 2236-2592 • Dossiê:

\section{Discursos de resistência e corpos (re)existentes •}

impasse em que se encontra. Assim, diante das mudanças que começaram a acontecer na vida de Gabriel, ele conta como encarou tal situação no ambiente escolar e nas relações com a sua família:

Foi difícil assim, eu lembro que com nove anos, minha mãe me levou no ginecologista. Ele falou, tá muito estranho, tá nascendo seios, você tem nove anos, eu fiquei, estranho mesmo, porque não era para isso tá acontecendo e daí a gente foi, foi terrível, nossa, porque eu ficava pensando, o que, que eu tô fazendo aqui? Por que essas coisas estão acontecendo? E eu me lembro de um dia estar sozinho em casa e meu irmão tinha uma daquelas faixas de pôr no pé para jogar bola, eu acho que é faixa o nome daquilo, aquelas brancas. E aí eu coloquei nos seios, assim, muito, muito inocente sabe, eu não tinha ideia, eu só achava que aquilo não tinha que estar ali. E aí eu estava sozinho em casa por algum momento assim, que eu não me lembro. Mas eu lembro de colocar e ficar andando pela casa e pensando, ah será que se eu usar isso, eles vão parar de crescer, e também pensando, como é que eu usaria aquilo sem ninguém perceber, eu tinha assim dez anos e não teria como minha mãe não perceber. E foi muito difícil a aceitação de que as coisas mudariam e a tentativa de adequação assim na adolescência, de pensar que eu tinha que me adequar aquilo que, que diziam que eu era e mesmo que eu soubesse que não, eu tinha que ser, eu não tinha outra opção, eu não sabia da existência de outras opções naquele momento, só me lembro de na infância pensar ser uma coisa e depois eu ter que ser outra coisa (GABRIEL, 2018, trecho 02).

No início do trecho 02 da fala de Gabriel, se manifesta a contraditoriedade de sua identidade de gênero que se contrapõe com o seu sexo biológico. Ao identificar a necessidade de ser tratada por um médico ginecologista, uma especialidade direcionada para problemas relacionados ao sexo feminino, Gabriel se via como um homem e buscava compreender o motivo pelo qual ele estava sendo tratado como uma mulher. Desse modo, observamos que o seu conflito modal é decorrente de uma tensão já existente no nível fundamental em que os termos se contradizem na medida em que ele se concebe de uma maneira e é visto de outro modo em suas interações, o que revela uma outra gramática da sexualidade para este sujeito. Assim, o dever-fazer que se relaciona com a necessidade de Gabriel ser consultado por um médico ginecologista causava-lhe angústia, dor e sofrimento, porque ser tratado e ser sujeitado a receber tratamento no feminino não condiziam com a sua identidade de gênero.

\footnotetext{
Stoller tinha como objetivo construir um argumento lógico. E, assim, para ele, o que definia o transexual, mais do que a demanda de cirurgia, era a convicção inabalável de ser "uma mulher no corpo de homem". Seu interesse era o desenvolvimento da feminilidade e da masculinidade, mas os estudos sobre transexuais apontavam as origens da identidade de gênero de forma muito mais clara que nas outras pessoas. O aporte original de seus estudos foi abordar a infância de meninos considerados biologicamente normais que ainda bem pequenos tinham muitas características femininas (andar, gestual, inflexão vocal...), usavam roupas ou as improvisavam com toalhas e outros adereços (JORGE; TRAVASSOS, 2018, p. 76, grifos nossos).
}

A figura dos seios que Gabriel destaca refere-se ao tema de feminilidade que ele busca afastar-se, uma vez que não era condizente com o autoconceito que ele possui. Um modo de 
PERcursos Linguísticos • Vitória (ES) •v. 10 •n. 25 • 2020 • ISSN: 2236-2592 • Dossiê:

Discursos de resistência e corpos (re)existentes •

eliminar essa presença feminina, ainda que por meio de um simulacro criado, momentaneamente, foi encontrada com o uso das faixas de seu irmão, que Gabriel utilizou com a finalidade de fazer desaparecer para si os seios. Gabriel buscava parecer algo que, biologicamente, ele não era. Ele acreditava que mascar ou esconder seus seios poderia fazê-lo se sentir como ele já se via internamente (um homem).

Gabriel almejava e tentava ser homem e não-parecer mulher, tratando-se de um segredo que ela desejava manter (seu gênero biológico). No entanto, quando ele começa a ter que frequentar o ginecologista, por exemplo, ele passa a parecer o que de fato ele biologicamente era. Dessa maneira, ao seu conflito interno (e modal) era acrescido o desejo de não ser biologicamente do sexo feminino (um querer-não-ser).

Segundo Landowski, "não basta apenas ser, é necessário também existir" ((LANDOWSKI, 2012). Para que isso ocorra, o primeiro passo rumo ao encontro com essa existência própria é adquirir a competência necessária que o modalizará para o poder-fazer o que quer-ser e, assim, entrar em conjunção com a sua identidade que almeja:

Entretanto, por outro lado, ser si mesmo não é apenas ser, ou afirmar-se "outro que não o Outro". É, ao mesmo tempo, um pouco mais que isso. No mínimo, é também simplesmente, "existir" (mais que não ser), é ser "alguém" ou "algo" (mais que nada) ou, em todo caso, ter a sensação de sê-lo. É “viver" dando, se possível, um sentido ao que se faz com sua própria vida ou, senão, tentando entender o que a própria vida faz de nós. É tentar captar o mínimo de coerência que dá sentido e unidade ao devir que faz com que cada um seja, individual ou coletivamente, o que é (LANDOWSKI, 2012, p. 26).

Ainda em relação trecho 02 da fala de Gabriel, os valores relacionados à sua mãe referem-se à normatividade que ele deveria seguir: se ele nasceu com o sexo biológico feminino, não deveria pensar em ser outra coisa a não ser mulher. Esconder os seios seria algo que a sua mãe não aprovaria, devido aos valores que ela mantinha consigo mesma.

A categoria semântica fundamental que se apresenta nessa parte do discurso de Gabriel é a liberdade vs. opressão, porque quando ele diz que tinha que viver e ser algo que não era, seu discurso está no polo da opressão que ele experienciava. A liberdade, em contrapartida, está relacionada com a possibilidade de ele ser homem, de acordo com o que previa a sua identidade de gênero. No entanto, até aquele momento, Gabriel estava completamente disjunto da liberdade.

Gabriel buscava, por meio da programação (LANDOWSKI, 2014), convencer-se de que não existia outro caminho, senão aceitar que ele estava destinado e condicionado a viver preso em um corpo feminino, que não era condizente com a maneira como ele se sentia psicologicamente. Manifesta-se ainda a tentativa de Gabriel estar em conjunção com o Sr. Todo Mundo (família, amigos e pessoas do convívio social = escola), ainda que ele precisasse se 
PERcursos Linguísticos • Vitória (ES) •v. 10 •n. 25 • 2020 • ISSN: 2236-2592 • Dossiê:

Discursos de resistência e corpos (re)existentes •

camuflar (internamente) como um camaleão (LANDOWSKI, 2002), vestindo uma roupagem que não expressava quem ele era e como ele se sentia de fato, para poder interagir e se sentir aceito pelos demais, sem a ocorrência de nenhum tipo de preconceito ou possibilidade de segregação ou exclusão.

A identidade dos sujeitos que se relacionavam com Gabriel tinha semelhanças físicas com ele. No entanto, sob a perspectiva dele mesmo, eram alteridades coerentes entre elas, mas muito distantes do modo como ele se enxergava. Landowski aponta que:

[...] o que dá forma à minha própria identidade não é só a maneira pela qual, reflexivamente, eu me defino (ou tento me definir) em relação à imagem que outrem me envia de mim mesmo; é também a maneira pela qual, transitivamente, objetivo a alteridade do outro atribuindo um conteúdo específico à diferença que me separa dele (LANDOWSKI, 2012, p. 04).

Esse objeto que Landowski menciona, refere-se, no caso de Gabriel, à identidade de gênero dessas alteridades com as quais ele se relaciona, que estão em consonância com a corporeidade e o sexo biológico delas, o que é diferente dele, que vive em um corpo que é dissonante de sua identidade de gênero.

Em seguida, Gabriel conta como foi em sua adolescência, o processo de lidar com o seu corpo e questões relacionadas à sua sexualidade:

\begin{abstract}
E aí na adolescência, foi um processo de tentar me aproximar da feminilidade, de tentar ter uma vivência enquanto uma mulher cis e me adequar aos padrões sociais do que é ser uma mulher, de como é que a gente se porta, de como é que a gente é, se veste, de como é que a gente fala, de como é que a gente está nos lugares assim e foi difícil, muito difícil. Porque não era, eu não estava naquele lugar, por mais que eu tentasse, não era eu, eu me via no espelho e as coisas estavam muito estranhas, eu estava tentando ser alguma coisa, que eu não era. Parecia que eu estava fantasiado de alguma coisa, como se a fantasia não acabasse assim, eu tinha que viver ela todos os dias e não era uma fantasia que eu gostava (GABRIEL, 2018, trecho 03).
\end{abstract}

Logo no início da fala de Gabriel, se apresenta o tema de passagem da infância para a adolescência e da continuidade de seus conflitos identitários internos. Mesmo assim, optou por tentar parecer e se comportar como uma mulher, algo que ele reitera, em vários momentos, que não era.

A tentativa de se aproximar da feminidade causava sofrimento para Gabriel ao destacar como isso "foi difícil, muito difícil". Ele buscava criar um simulacro que concebesse a ideia de que de fato ele era um sujeito que condizia com o corpo no qual buscava performativizar seu gênero (feminino). A performatividade e os atos corporais que Gabriel buscava apresentar e desenvolver socialmente se relacionavam com o gênero e a identidade feminina, pois ele destaca que tentava se comportar, falar e se vestir como uma mulher, na tentativa de evitar e lidar com os conflitos relacionados à sua identidade de gênero (biológica), à pressão social e interna. 


\section{PERcursos Linguísticos • Vitória (ES) •v. 10 •n. 25 • 2020 • ISSN: 2236-2592 • Dossiê: \\ Discursos de resistência e corpos (re)existentes •}

Se a performatividade é algo linguístico, como os atos corporais se tornam performativos? Essa é a pergunta que devemos nos fazer se queremos entender a formação de gênero, mas também a performatividade das manifestações de massa. No caso de gênero, as primeiras inscrições e interpelações são acompanhadas pelas expectativas e fantasias de outras pessoas, todas elas nos afetam nos aspectos que inicialmente estão além do nosso controle: as normas nos são impostas em termos psicossociais e pouco a pouco eles nos instigam. Aparecem quando não se espera e abrem espaço dentro de nós, incentivando e estruturando nossas próprias formas de responsabilidade. Elas não são padrões que são simplesmente impressos em nós, colocando marcas e rótulos a tantos destinatários passivos de uma máquina cultural. Essas regras também nos produzem, mas não no sentido de que acreditam em nós ou determinam estritamente quem somos. O que elas pretendem é moldar estilos de vida corporizados que adquirimos ao longo do tempo, e essas mesmas modalidades de corporização podem se tornar uma maneira de expressar rejeição a essas mesmas normas, e até mesmo romper com elas (BUTLER, 2017, p. 36, tradução nossa) ${ }^{7}$.

No sentido que Butler apresenta de performatividade e as relações com a corporização, é possível compreender que "ao moldar esses estilos de vida corporizados" socialmente é concebida a ideia e criado um simulacro que faz-crer que, se um sujeito que nasceu com o sexo masculino, deve seguir o modelo (por vezes naturalizado) que defende que ele será homem pertencente à categoria do masculino, impossibilitando-o de se identificar com um gênero distinto do seu sexo biológico.

O conflito identitário experienciado por Gabriel durante a sua adolescência aponta o seu fazer interpretativo, uma vez que ele, ao identificar o predomínio e linearidade dos modos como a figura feminina deveria ser, agir e se comportar, ele introjeta o modelo e busca replicá-lo em seu modo de ser, na tentativa de se auto convencer de sua feminilidade e ser aceito socialmente, mesmo que isso lhe cause sofrimento. Diante do conflito identitário experienciado por Gabriel, ele conta como encarava tudo que estava acontecendo.

Eu pensava que eu não podia contar para as pessoas. Como é que eu ia, por exemplo, a minha mãe, que é uma pessoa mais próxima assim ou algum amigo muito próximo da escola, como é que eu ia contar para alguém, que estava acontecendo isso. Sendo que a normalidade para todas as pessoas é, você é o que é você, é assim, o que você nasceu, o que disseram que você é a verdade, né. E aí, eu não falava com ninguém e aí na adolescência veio, as questões de sexualidade, eu pensava, ah deve ser por isso, achei o meu caminho e a minha resposta e tudo está resolvido. Mas o incômodo não acabava, o incômodo não era sobre a sexualidade, o incômodo era sobre a identidade,

\footnotetext{
${ }^{7}$ Texto original: si la performatividad es algo lingüístico, ¿cómo se convierten los actos corporales en performativos? Esta es la cuestión que tenemos que plantearnos si queremos entender la formación del género, pero también la performatividad de las manifestaciones multitudinarias. En el caso del género, esas primeras inscripciones e interpelaciones van acompañadas de las expectativas y fantasías de los demás, todas las cuales nos afectan en aspectos que en un principio escapan a nuestro control: las normas se nos imponen en términos psicosociales y poco a poco se nos inculcan. Aparecen cuando ya no se las espera, y se abren paso en nuestro interior, animando y estructurando nuestras propias formas de responsabilidad. No son normas que simplemente se impriman en nosotros, poniéndonos marcas y etiquetas como a tantos destinatarios pasivos de una máquina cultural. Estas normas también nos producen, pero no en el sentido de que nos creen o determinen en sentido estricto quiénes somos. Lo que hacen más bien es dar forma a modos de vida corporeizados que adquirimos a lo largo del tiempo, y estas mismas modalidades de corporeización pueden llegar a convertirse en una forma de expresar rechazo hacia esas mismas normas, y hasta de romper con ellas.
} 


\section{Discursos de resistência e corpos (re)existentes •}

muito, muito antes do que a sexualidade. Que a sexualidade, eu vejo hoje, que a gente constrói depois da identidade, eu não consigo construir uma sexualidade sobre alguém que eu não sei quem é, assim, falando de mim, né. É difícil construir uma sexualidade em cima de uma identidade que eu não tinha que eu não consegui construir verdadeiramente antes. Mas aí ela eu não falava com as pessoas, eu não buscava nenhuma ajuda, aí eu lembro de uma vez na escola, assim com uns quatorze anos, eu fui até a coordenadora e perguntei para ela se tinha psicólogo na escola, ela tinha, mas ela saiu, aí eu perguntei: ah, mas não tem nenhum atendimento, nada? E eu não entendia muito bem também para que servia o psicólogo, mas eu tinha ouvido alguém falar que, ah, eles ajudam as pessoas, ah tudo bem, né, talvez eu possa conversar com alguém que me ajude, que me esclareça e aí ela falou que não tinha e, por mais que eu estudasse em uma escola particular assim, que eu era bolsista, ainda assim não tinha. É, fico pensando em alguém que estuda em uma escola menos privilegiada do que essa, mais difícil ainda. Mas aí ela só disse que não tinha possibilidade, aí depois desse dia eu falei ah, acho que eu não posso fazer nada com isso mesmo, tenho que só, deixar as coisas como são (GABRIEL, 2018, trecho 04).

A oposição semântica fundamental que se apresenta no início da fala de Gabriel é público vs. privado, pois ele buscava manter oculto para os demais a existência de tais conflitos identitários que ele experienciava. Esse ocultamento ocorria pelo medo que ele sentia de não ser compreendido ou ser sancionado negativamente por sua mãe ou por seus amigos.

Algumas figuras presentes no discurso de Gabriel revelam temas por ele experienciados, entre elas, podemos destacar: a figura do psicólogo que tematiza a busca por respostas que Gabriel detinha em relação à sua identidade e sua sexualidade; a figura da escola particular, lugar onde são concebidos diversos tipos de conhecimentos, tematiza a diversidade, uma vez que nela estão inseridos diversos sujeitos, que assim como Gabriel, experienciam conflitos internos relacionados a sua sexualidade, orientação sexual e identidade de gênero.

O retorno negativo da coordenadora da escola de Gabriel, relacionado ao atendimento psicológico que ele buscava, desencadeou a reiteração da crença de que ele não poderia fazer mais nada, senão conviver com aquela situação para ele inominada. Diante da situação que se apresenta, Gabriel segue disjunto do seu objeto de valor (questão identitária). Esse distanciamento ocorre porque, além dele não ter a competência necessária para responder o que se passa em relação à sua identidade, gênero e sexualidade, a sua busca pelo sujeito competente que possa realizar tal performance falha, ele não encontra tal sujeito e a apreensão do seu objeto de valor, se vê como algo distante, quase impossível, e Gabriel se faz crer que deverá viver com tal incompletude.

A seguir, Gabriel conta sobre a sua descoberta da existência de pessoas trans. Isso foi um fato marcante em sua trajetória de busca por respostas. 
PERcursos Linguísticos • Vitória (ES) •v. 10 •n. 25 • 2020 • ISSN: 2236-2592 • Dossiê:

\section{Discursos de resistência e corpos (re)existentes •}

trans que não tem emprego, não tem o que fazer, é a única forma de sobrevivência, então que eu conheci, era isso sabe? O que as pessoas ficam fazendo piada de traveco, essas coisas, era o que eu sabia, o que eu conhecia, aí eu ficava pensando que não, não, não é assim que eu sou, e eu não conseguia, e eu não via outra coisa, outro, outro tipo de identidade para eu ter (GABRIEL, 2018, trecho 05).

No primeiro contato de Gabriel com a existência de pessoas trans, ele aponta a presença dos seus preconceitos, ancorados pelo senso comum, que apontavam o simulacro construído socialmente, que definia a figura do sujeito trans e do travesti, tematizando a promiscuidade, prostituição e o desemprego, e sempre eram vinculados a valores negativos/disfóricos. Desse modo, Gabriel se negava a aceitar que a sua identidade era de uma pessoa trans, porque ele não se via daquele modo, construído socialmente pela massa social predominantemente orientada por valores heteronormativos. Trata-se do medo da estigmatização que Gabriel poderia sofrer, ao passar a pertencer à categoria/comunidade de pessoas trans (com significados e sentidos disfóricos que lhes são atribuídos). Segundo Goffman, em seus estudos sobre estigma social, ele destaca que:

O indivíduo estigmatizado pode mostrar uma ambivalência de identidade quando vê de perto que eles comportam-se de um modo estereotipado, exibindo de maneira extravagante ou desprezível os atributos negativos que lhes são imputados. Essa visão pode afasta-lo, já que, apesar de tudo, ele apoia as normas da sociedade mais ampla, mas a sua identificação social e psicológica, com esses transgressores o mantém unido ao que repele, transformando a repulsa em vergonha e, posteriormente, convertendo a própria vergonha em algo de que se sente envergonhado (GOFFMAN, 2004, p. 93).

No caso de Gabriel, até o presente momento, ele não se define como sujeito trans. Essa incerteza demonstra que ele está no estágio de repulsa, quando pensada a identidade trans, porque os atributos (negativos) imputados a essa identidade não condizem com a realidade de Gabriel e o que ele espera para o seu futuro.

Os percursos temáticos figurativos, que contemplam o sujeito trans e o sujeito travesti, concebem a promiscuidade e a repulsa (como valores que os caracterizam) e a exclusão dessas identidades, quando pensada a possibilidade de auto identificação de Gabriel com essa categoria (identidade de gênero). No momento em que Gabriel descreve as características do sujeito trans e do travesti, se apresenta o regime de interação por exclusão (LANDOWSKI, 2002), uma vez que ele exclui e rejeita qualquer possibilidade de assimilar essa identidade como alteridade ou como identidade dele próprio. Essa exclusão parte do simulacro construído pelo sujeito intolerante que caracteriza e categoriza a identidade trans, dotada de atributos negativos/disfóricos. 
PERcursos Linguísticos • Vitória (ES) •v. 10 •n. 25 • 2020 • ISSN: 2236-2592 • Dossiê:

Discursos de resistência e corpos (re)existentes •

Gabriel defende que sua busca é estritamente voltada pelo conhecimento teórico desse tipo de identidade (trans) que, segundo ele, nunca tinha ouvido falar e que lhe desperta tanta curiosidade.

\section{A (in)visibilidade e a (im)possibilidade do sujeito trans no contexto universitário}

Gabriel destaca sua busca como algo relacionado ao conhecimento, como algo externo, e não concernente a uma motivação interna. É possível pensar que, uma vez que ele estava conhecendo esse universo até então inexplorado, ao identificar histórias permeadas por dramas, conflitos internos e relações delicadas, contadas pela travesti que ele conheceu, e em seguida por seu amigo, que os sujeitos trans vivenciam a possibilidade dele poder-ser um homem trans, causava-lhe medo do que ele poderia experienciar, e com o que ele teria que lidar e enfrentar caso se assumisse como homem trans:

\footnotetext{
E aí eu fiquei dois anos lendo coisas e sofrendo assim, porque eu sabia que eu não estava só lendo para conhecer, que eu não estava só, aí eu tô muito curioso, eu quero entender, eu quero, não precisava de tudo aquilo só para entender. Eu estava buscando coisas que eram minhas, que estava ali, no meio daquilo tudo, que eu tinha que ir lá achar de algum jeito. E, em 2017, eu comecei a fazer terapia, é, no começo de 2017, porque eu estava tendo crises de ansiedade, e eu, não, agora estudando Psicologia, eu não vejo como coincidência, ah os períodos das coisas assim sabe. A partir do momento que eu começo a entrar muito perto, de coisas que eram muito difíceis para mim, eu comecei a ter crise de enxaqueca, que eram todas emocionais, comecei a ter crises de ansiedade, que eram todos emocionais e, assim, era terrível, eu não conseguia fazer coisas normais assim, eu ficava com medo de sair de casa, comecei a ter fobia social e foi muito, muito difícil, porque aí eu não conseguia nada, tudo ficou muito difícil para mim, entrei no estágio depressivo terrível assim. E a terapia me ajudou assim no começo e depois eu parei de ir, porque era difícil também, eu não tinha outra opção, a não ser falar, a não ser pensar as minhas coisas e naquele lugar sabe, passar aqui de 50, 60 minutos, ficou muito difícil. E aí eu parei de ir, no meio do ano passado fui só uns quatro, cinco meses e parei e aí fiquei uns dois meses sem ir (GABRIEL, 2018, trecho 07).
}

Gabriel descreve que ele reconheceu que se tratava de uma motivação interna, de questões que eram relacionadas com a sua própria descoberta identitária, que ele estava engajado em descobrir mais informações sobre a identidade trans. Em decorrência dos conflitos internos e das descobertas presentes na vida de Gabriel durante esse período, tais situações conceberam a ansiedade, em que ele buscou, por meio do acompanhamento psicológico, solucionar/amenizar esse problema. Trata-se aqui da somatização de algo não físico (crise identitária) que passava a conceber efeitos físicos, como as crises de ansiedade e crises de dores de cabeça (enxaqueca).

Além disso, o medo começou a intensificar-se e Gabriel desenvolveu fobia social e um quadro severo de depressão. Tais situações foram decorrentes das constatações a que ele 
PERcursos Linguísticos • Vitória (ES) •v. 10 •n. 25 • 2020 • ISSN: 2236-2592 • Dossiê:

Discursos de resistência e corpos (re)existentes •

chegou, por meio dos estudos e do contato com pessoas da comunidade trans. Mesmo Gabriel identificando sua melhora quando estava frequentando a terapia, em determinado momento ele passou a se ver confrontado, não com a figura do terapeuta em si, mas com ele mesmo. Naquele espaço do setting terapêutico, ele não teria outra opção a não ser lidar com o que ele buscava negar a aceitar: a sua identidade de gênero e os desdobramentos implicados ao assumir essa nova condição.

A oposição semântica fundamental que se apresenta nesse fragmento da fala de Gabriel é saúde vs. doença, em que a sua saúde foi abalada e bombardeada por diversos problemas e doenças de ordem psíquica, uma vez que Gabriel começou a sua trajetória de busca pelo autoconhecimento, e passou a desvelar caminhos que pudessem mostra-lo, elementos que ele almejava conhecer relacionados à sua formação identitária, mas que ainda ele não havia adquirido maturidade (competência) necessária para lidar e dar conta naquele momento de sua vida.

No trecho seguinte, Gabriel conta um episódio marcante em sua trajetória: a tentativa de suicídio devido ao momento delicado que o jovem estava enfrentando em sua vida.

\begin{abstract}
Em agosto do ano passado, eu tentei suicídio, porque eu sabia, eu cheguei em um ponto que eu sabia, o que estava acontecendo, eu sabia quem era, eu sabia de tudo. E eu achava que não era possível, não é possível eu ser uma pessoa trans, não é possível eu querer estar nesse lugar, que é tão, não é um lugar. Sabe o que colocam para pessoas trans e travestis, não existe um lugar. É um corpo muito abjeto, assim, muito distante, muito marginalizado e eu não queria esse lugar para mim, eu achava que era impossível eu lidar com tudo isso e viver dessa maneira, de um jeito de viver mesmo, não só existir nas margens da sociedade ou nas margens de todas as coisas, porque não existe emprego, não existe uma escola que não violente, não existe faculdade que não seja terrível assim, era o que eu ficava pensando, né? E aí eu fiquei que, eu sei o que eu sou, eu sei o que tá acontecendo, então assim, já que eu não consigo lidar com isso, vou ter que morrer, porque não dou conta disso e aí foi um episódio muito difícil, que eu tomei um monte de remédio e tudo e aí eu escrevi uma carta para minha mãe e para os meus amigos e aí eu só dizia eu não consigo mais, mas eu amo vocês e tudo. E aí eu fiquei apagado uns três dias assim e daí a minha mãe leu, porque eu tinha deixado em cima da mesa, assim no quarto e aí um monte de amigos foram lá e ninguém entendendo o que estava acontecendo, porque eu não falava com ninguém assim, diretamente, o que era comigo, que estava acontecendo comigo, o que eu não sabia lidar, eu não conseguia falar. E aí depois disso, a minha mãe ficou muito preocupada assim e eu sinto que nesse momento foi uma virada assim, dela ter um outro olhar, e pensar, tem alguma coisa errada, além do que eu, já estava lá, do que ela já viu que estava acontecendo, né? (GABRIEL, 2018, trecho 08).
\end{abstract}

A categoria semântica fundamental presente no início do trecho 08 é vida vs. morte. A vida de Gabriel que foi colocada em risco com a tentativa de suicídio, quando ele se deu conta de quem ele era causou-lhe um desequilíbrio emocional, fazendo com que ele buscasse, na tentativa de suicídio, resolver de maneira rápida o conflito que se revelou a ele, ser um homem 
PERcursos Linguísticos • Vitória (ES) •v. 10 •n. 25 • 2020 • ISSN: 2236-2592 • Dossiê:

Discursos de resistência e corpos (re)existentes •

trans, e poder-ser um homem trans, diante de todas as informações e conhecimentos que Gabriel havia adquirido até aquele momento.

O medo de pertencer a um não-lugar, como Gabriel mesmo define para a comunidade trans, o paralisou, porque até aquele momento de descoberta, Gabriel ocupava um lugar, de mulher cisgênero. No entanto, não o seu lugar, porque ele não se sentia daquela maneira, e agora, programando-se para aceitar-se como homem trans "diferente", ele teria sua identidade de gênero concernente com o modo como ele se sentia. Pensando nos regimes de interação, nos espaços sociais e nas relações que ele mantinha até o momento, tudo se tornaria diferente, pois ele estaria rompendo com os contratos e pactos sociais até então respeitados e aceitos. Gabriel naquele momento já conhecia como era a trajetória percorrida pelo sujeito trans, e temia o que no futuro ele poderia vivenciar.

O modo como Gabriel descreve o sujeito trans, como está inserido na sociedade e nos espaços sociais, os valores que estão presentes em todas suas relações são disfóricos. Nesse momento também fica claro o motivo da resistência de Gabriel no passado, por ter se resistido inicialmente a aceitar a sua identidade de gênero, pois ele sabia que a identidade trans é modalizada pelo não-dever-ser e do não-poder-fazer devido à sua condição de alteridade.

Outro ponto importante são as figuras presentes no discurso de Gabriel, entre elas a de sua mãe e os seus amigos, que tematizam as relações e apoio familiar afetivo que foi fundamental para que Gabriel pudesse superar aquela fase tão delicada de sua trajetória de vida. A carta que Gabriel havia escrito para as pessoas com quem ele possuía laços afetivos também tematiza o amor que ele sentia por aquelas pessoas, a dificuldade e o conflito interno que ele enfrentava, no qual ele viu como única saída, acabar com a sua própria vida.

Após esse momento delicado na vida de Gabriel, ele retornou ao acompanhamento psicológico, que lhe possibilitou ver na figura da psicóloga, alguém que ele pudesse confiar, que não ocupasse o lugar de sujeito julgador que tratasse da transexualidade dele como fenômeno psicopatológico, como outros psicólogos fizeram no passado.

E aí eu voltei para, a terapia e aí lá eu consegui assim, me achar, eu consegui entender que tava tudo bem, tive muita sorte de ir numa psicóloga, que não disse que eu tinha um transtorno mental, que não veio falar comigo com o CID na mão e me colocar dentro de um monte de laudos e outras coisas. E ela me ajudou muito assim, a sair de um lugar que eu achava que era impossível sair de lá, eu sentia que eu tava num buraco assim, tão fundo, que não podia, e aí foi uma virada assim, na minha vida, de, tá bom, já que não aconteceu nada e eu tô aqui ainda, e, tenho que lidar com as coisas, eu vou fazer alguma coisa sobre isso. E aí, eu resolvi o que eu ia fazer assim, há um ano e um mês atrás, eu resolvi que eu tinha que falar sobre isso, que eu tinha que contar para as pessoas, que eu tinha que ser quem eu era, que eu tinha que me sentir confortável sendo eu, verdadeiramente assim, depois de vinte e um anos eu tinha que ser quem eu sou, não tinha outra, outra opção, eu não podia mais fingir, não podia estar mais num lugar que não era o meu lugar. Eu não podia mais, ser quem eu não era, e daí eu contei 
para minha mãe, contei para os amigos, e no final, assim, no final não né, no final depois de ter contado, eu comecei a pensar e perceber que a gente pode criar outros lugares, estar em outros espaços, e, que é muito difícil, sempre é muito difícil, mas ter uma pessoa é melhor do que não tem nenhuma pessoa. Você falar sobre isso, num lugar que não tem ninguém que fale sobre isso, já é fazer as pessoas repensarem sabe. Foi muito difícil, mas consegui, conseguir dizer, conseguir ser quem eu sou, e, nossa foi a melhor coisa que eu fiz (GABRIEL, 2018, trecho 09).

Quando Gabriel conta que se sentia como se estivesse em um buraco, esta figura tematiza a depressão, o medo, a impossibilidade de existir e opressão que ele vivenciou quando o jovem se deu conta de que ele era um homem trans. No entanto, a psicóloga que o acompanhava atuou como facilitadora do processo de auto descoberta e auto aceitação da identidade do jovem.

Ao relatar que começou a se sentir melhor após se identificar como homem trans e aceitar a sua identidade de gênero, Gabriel passa a significar a identidade trans de maneira eufórica e o elemento que reitera essa questão se relaciona com a frase final do trecho 09 de seu discurso: "foi a melhor coisa que eu fiz", pois daquele momento em diante, ele passou a se sentir melhor, realizado, e seguro de si mesmo, com a convicção de qual era a sua identidade.

Após adquirir a competência necessária (autoconfiança) para contar aos seus familiares e amigos que ele era um homem trans, Gabriel conclui a sua performance e revela para todos qual é a sua identidade. Além disso, ele decide criar outros sentidos em sua história de vida, buscando criar outros espaços e novas configurações que contemplem a comunidade trans, ressignificando a existência dessa identidade com elementos e características distintas daqueles que ele conheceu inicialmente. Ele conta como foi lidar as suas descobertas e transição identitária no contexto universitário.

Durante, foi muito difícil né, porque foi no segundo semestre do primeiro ano, eu não conseguia ir para a faculdade, eu não me sentia bem e Psicologia tem muito dessas coisas, de trabalho em grupo, e seminário, apresentação em público, era terrível para mim, eu não dava conta de fazer essas coisas, e aí eu quase fiquei, bombei o semestre todo né, por que não dava, eu tinha mais de 3 matérias de DP. Mas aí eu tive uns professores muito compreensivos assim, eu não contei exatamente o que tava acontecendo, só falei as coisas não estavam muito bem, e tava óbvio assim, que eu tava com algum problema psicológico difícil naquele momento, de ansiedade tudo. $\mathrm{E}$ aí, ainda bem que eu tive muito entendimento sobre isso e aí fiz as provas finais e consegui passar o semestre. E aí quando eu tive que voltar esse ano né, e eu decidi que eu voltaria como eu sou, que eu não, não ficaria fingindo que não estava acontecendo, é... eu pensei em trancar o curso e não fazer, porque achei que ia ser um espaço muito violento assim, mas ai eu vou assim, ah vou tentar né (GABRIEL, 2018, trecho 10).

Em seu relato Gabriel conta que durante o seu processo de descobertas, a experiência no contexto universitário foi bastante difícil para ele, o que afetou seu rendimento acadêmico, fazendo-o repetir todo o semestre devido à sua dificuldade em frequentar o ambiente da 
PERcursos Linguísticos • Vitória (ES) •v. 10 •n. 25 • 2020 • ISSN: 2236-2592 • Dossiê:

\section{Discursos de resistência e corpos (re)existentes •}

universidade. Ele destaca que o próprio curso acaba mobilizando estruturas psíquicas que, de algum modo, causam algum efeito. No caso dele, com a somatização do que estava em desordem na sua constituição identitária, ele se via confrontando quando estava em aula.

A necessidade de parecer (algo que ele não era, agora ciente disso, que de fato ao estava de errado) e o dever-fazer apresentar trabalhos e seminários em aula, lhe causava desconforto, quando ele se encontrava em conjunção com a identidade da sala como um todo.

A categoria semântica fundamental que se apresenta nos fragmentos finais do discurso de Gabriel é público vs. privado, quando ocorre também uma mudança de estado relacionada à identidade e aos modos de presença de Gabriel. Anterior à sua descoberta identitária, a sua identidade de gênero era escondida dos demais alunos e professores de Gabriel, até porque ele mesmo não sabia se auto definir, o que tematiza o conflito identitário experienciado por ele. Após Gabriel descobrir-se como homem trans, ele decide regressar à universidade, agora com a sua identidade de gênero assumida, tornando-a pública.

Havia um simulacro construído na mente de Gabriel de que o ambiente universitário poderia ser violento, mas ainda assim ele decidiu persistir e seguir frequentando, mesmo que houvesse pensamentos de medo ou insegurança. No trecho seguinte, Gabriel relata algumas situações que o deixaram desconfortável, relacionadas aos questionamentos da coordenadora do seu curso, que demonstrou, por meio dos seus comentários, a existência de um preconceito velado, segundo a visão de Gabriel.

E aí fui conversar com a coordenadora do curso e ela assim, no quanto ela conseguiu, ela foi muito receptiva, nas limitações dela assim, que eu percebo que as pessoas têm muito ainda, ela foi muito receptiva e disse, não, porque eu estou, tô aqui, se você precisar de qualquer coisa, e não sei o que lá. Mas ao mesmo tempo, que ela disse que tava aqui, que tudo bem, que a gente podia mudar o nome nas listas, e tudo mais, aí ela perguntou para mim, se eu ia usar o banheiro feminino que era mais seguro, e aí eu fiquei meio... sabe, ela... é porque nossa você sabe a violência não sei o que. Daí eu perguntei para ela, mas você usa o banheiro masculino, e ela falou, não, aí eu falei então eu não uso feminino, e aí ela falou, ai mas têm todas essas questões, eu falei, eu sei que tem essas questões, mas as questões, sempre existem, se a gente ficar com medo de encarar as coisas, eu não ia estar nem aqui assim, na faculdade, não ia ter nem ido falar com ela, e aí foi muito receptivo assim, foi muito bom, e, aí eu troquei de sala, não fiquei na mesma sala que eu tava no ano passado e acho que foi ótimo, por que as pessoas da outra sala eram muito difíceis assim, em relação a isso, algumas vezes, uma vez na sala, teve uma discussão sobre, sobre feminismo e pessoas trans, e, aí falaram muitas coisas terríveis, e aí eu não aguentei só sai da sala assim, e foi mais um ponto, para eu não ir nas aulas direito. Mas aí esse ano, quando eu cheguei, eu não precisei falar, não precisei ficar, eu fico brincando que às vezes, a gente tem que dar mini palestras assim, de explicar coisas, eu não precisei fazer isso, as pessoas já sabiam mais ou menos. E aí uma professora decidiu que ela ia fazer uma, uma dinâmica com a sala, de colocar as pessoas em duplas e depois elas conversavam um pouco e depois elas tinham que apresentar o outro. E aí, eu sentei com uma menina que eu não conhecia assim, e a gente conversou, e aí quando ela foi me apresentar, as pessoas ficaram nossa, e a professora conduziu muito bem, que ela é ótima, maravilhosa, e, fez de um jeito muito, qual é a palavra que eu posso usar? Fez de um jeito muito didático assim, para as pessoas, e no final, as pessoas estavam muito 


\section{Discursos de resistência e corpos (re)existentes •}

receptivas e, perguntando para mim, aí será que eu posso fazer uma pergunta, e levantavam a mão, a gente tava numa roda assim, bem grande, e eu fiquei um pouco, nossa, pode né, e aí eu tava respondendo às perguntas, e algumas pessoas começaram a chorar assim, nossa, mas como é que você consegue, como é que você tá aqui, eu só pensando, eu não tinha outra opção, a não ser tá aqui, sabe, por que eu acho que desistir das coisas nunca é a melhor opção. Mas essa sala que eu tô, tem sido ótima, nunca aconteceu nada de ruim assim, mesmo a violência, nenhum preconceito, pelo menos para mim nunca falaram nada e tenho sido muito, eu tenho sido muito privilegiado assim (GABRIEL, 2018, trecho 11).

À princípio a coordenadora do curso de Gabriel se mostrou receptiva diante da situação do aluno. No entanto, quando ela o questiona sobre a utilização do banheiro feminino, Gabriel identifica a ação do preconceito e da discriminação, uma vez que ele se vê e se apresenta como homem, ele passaria, então, a frequentar o sanitário masculino. Essa constatação causou certo receio por parte da coordenadora, que alega que seu questionamento se dá porque ela se preocupa com a segurança ou com algum ato de violência que Gabriel poderia vir a sofrer se utilizasse o banheiro masculino.

Gabriel não aceita se sujeitar à manipulação por intimidação e questiona o destinador manipulador (coordenadora), fazendo-a refletir sobre a mesma situação, sendo ela mesma a protagonista da história, e a resposta dela é mesma que a Gabriel, que mantém a sua escolha de utilizar o banheiro masculino. Após esse momento em que a coordenadora tentou convencer Gabriel de continuar utilizando o banheiro masculino, ele destacou que havia se arrependido de recorrer a ela nessa situação, pois encarou aquela atitude como uma manifestação de preconceito, mas ainda assim, seguiu em frente, e reconhece que fora esse episódio ele havia se sentido bem recebido e compreendido diante de sua nova realidade no contexto universitário.

Em sua nova turma, Gabriel pode compartilhar com os demais alunos algumas informações e a sua experiência de descoberta identitária. Segundo o próprio, todos o aceitaram como alteridade, sem quaisquer tipos de julgamentos e isso o confortou e permitiu que ele se sentisse acolhido por todos.

Nos momentos finais do depoimento de Gabriel, algumas pessoas se emocionaram ao escutarem as experiências compartilhadas por ele. Identificamos que elas foram atravessadas pelas paixões da compaixão e da piedade, quando algumas delas destacaram que não podiam imaginar como Gabriel teria suportado e enfrentado aquela situação.

A compaixão e a piedade, o pavor e o medo, etc., servem bem para ilustrar a questão colocada. De um modo geral, a compaixão e a piedade, por exemplo, são concebidas como um sentimento de pesar que o infortúnio de outrem nos desperta; há, todavia, a marca de uma verdadeira partilha do sofrimento, um "sentir com", na primeira, enquanto na segunda configura-se uma assimetria de lugares, própria a um "sentir por", mais relacionado ao dever, à virtude. Essa sutil diferença, advinda da etimologia dos termos, faz com que o crer-saber o padecimento do outro, típico ao pesar em ambos os casos, seja de natureza qualitativa diferente. Na compaixão ele instaura o 
PERcursos Linguísticos • Vitória (ES) •v. 10 •n. 25 • 2020 • ISSN: 2236-2592 • Dossiê:

Discursos de resistência e corpos (re)existentes •

querer-ser do compassivo em relação ao sofredor, na piedade, o dever-ser para o piedoso. Assim, se o princípio estruturador (o crer-saber) é o mesmo nos dois estados de alma, o "ser do ser", ou, melhor dizendo, "o ser do crer" é sobredeterminado, em cada um deles, por predicados modais diversificados - pelo querer no caso da compaixão e pelo dever, na piedade (PORTELA et. al., 2012, p. 102).

Quando os alunos se emocionaram e choraram ao escutarem as palavras de Gabriel, eles sentiram com ele e por ele paixões que se aproximaram daquelas que ele mesmo sentiu, quando vivenciou as experiências contadas. Tratou-se de um querer-ser motivado e revelado pelos alunos relacionado ao sujeito sofredor, Gabriel, e o dever-ser relacionado aos alunos que foram piedosos após serem apresentadas as experiências de Gabriel.

\section{Considerações finais}

Diante do que foi apresentado ao longo dos capítulos analíticos que desvelam diferentes nuances do preconceito e da estigmatização do sujeito transgênero, é possível compreender à priori, a complexidade que reside no percurso de descoberta/(re)descoberta identitária, até que seja possível que o sujeito trans entenda o que se passa em relação à constituição de sua identidade de gênero.

Além disso, as relações complexas que são estabelecidas com os familiares, amigos e no contexto acadêmico de uma pessoa trans, apontam para o lugar onde a diversidade habita, onde impera predominantemente, e por vezes velada, ou em outras, manifestada, a ação do preconceito e da negação em aceitar o diferente, e mais do que isso, presentificam-se os regimes de interação, sobretudo de exclusão/admissão/segregação quando pensadas as relações entre identidade vs. alteridade.

\section{Referências}

AHMED, S. Queer phenomenology, London: Duke University Press, 2006.

BORDIEU, P. A dominação masculina. Trad. Maria Hehmedhlena Kuhner. - $2^{\mathrm{a}}$ ed. Rio de Janeiro: Bertrand Brasil, 2002.

BUTLER, J. Cuerpos aliados y lucha política. Hacia una teoría performativa de la asamblea. Traducción: María José Viejo. Paidós: Barcelona; Buenos Aires e México, 2017.g

GOFFMAN, E. Estigma: notas sobre a manipulação da identidade deteriorada. (1963). Tradução: Mathias Lambert, 2004.

JESUS, J. G. Orientações sobre identidade de gênero: conceitos e termos / Jaqueline Gomes de Jesus. Brasília, 2012. 
PERcursos Linguísticos • Vitória (ES) •v. 10 •n. 25 • 2020 • ISSN: 2236-2592 • Dossiê:

Discursos de resistência e corpos (re)existentes •

JORGE, M. A. C.; TRAVASSOS, N. P. Transexualidade: o corpo entre o sujeito e a ciência. Rio de Janeiro: Zahar, 2018.

LANDOWSKI, E. Presenças do Outro: ensaios de sociossemiótica. Tradução: Mary Amazonas Leite de Barros. São Paulo: Perspectiva, 2012.

LOURO, G. L. Gênero, sexualidade e educação: Uma perspectiva pós-estruturalista. $6^{\mathrm{a}}$ ed. Petrópolis, RJ: Vozes. 1997.

MAIA, G. F.; PIRES, G. As Transformações no Dispositivo da Transexualidade a partir da Luta pela Despatologização. Seminário Internacional Demandas Sociais e Políticas Públicas na Sociedade Contemporânea, 2019.

MODESTO, E. Transgeneridade: um complexo desafio. Via Atlântica, São Paulo, vol. 1, no 24, dez. 2013, p. 49-65.

PORTELA, J. C.; et al. (Orgs.) Semiótica: identidade e diálogos - São Paulo: Cultura Acadêmica, 2012. 